\title{
Habitar el cuerpo. Etnografía feminista desde los cuerpos de mujeres de San Basilio de Palenque*
}

Inhabiting the body. Feminist ethnography from the bodies of women of

San Basilio de Palenque

Habitar o corpo. Etnografia feminista dos corpos das mulheres de

San Basilio de Palenque

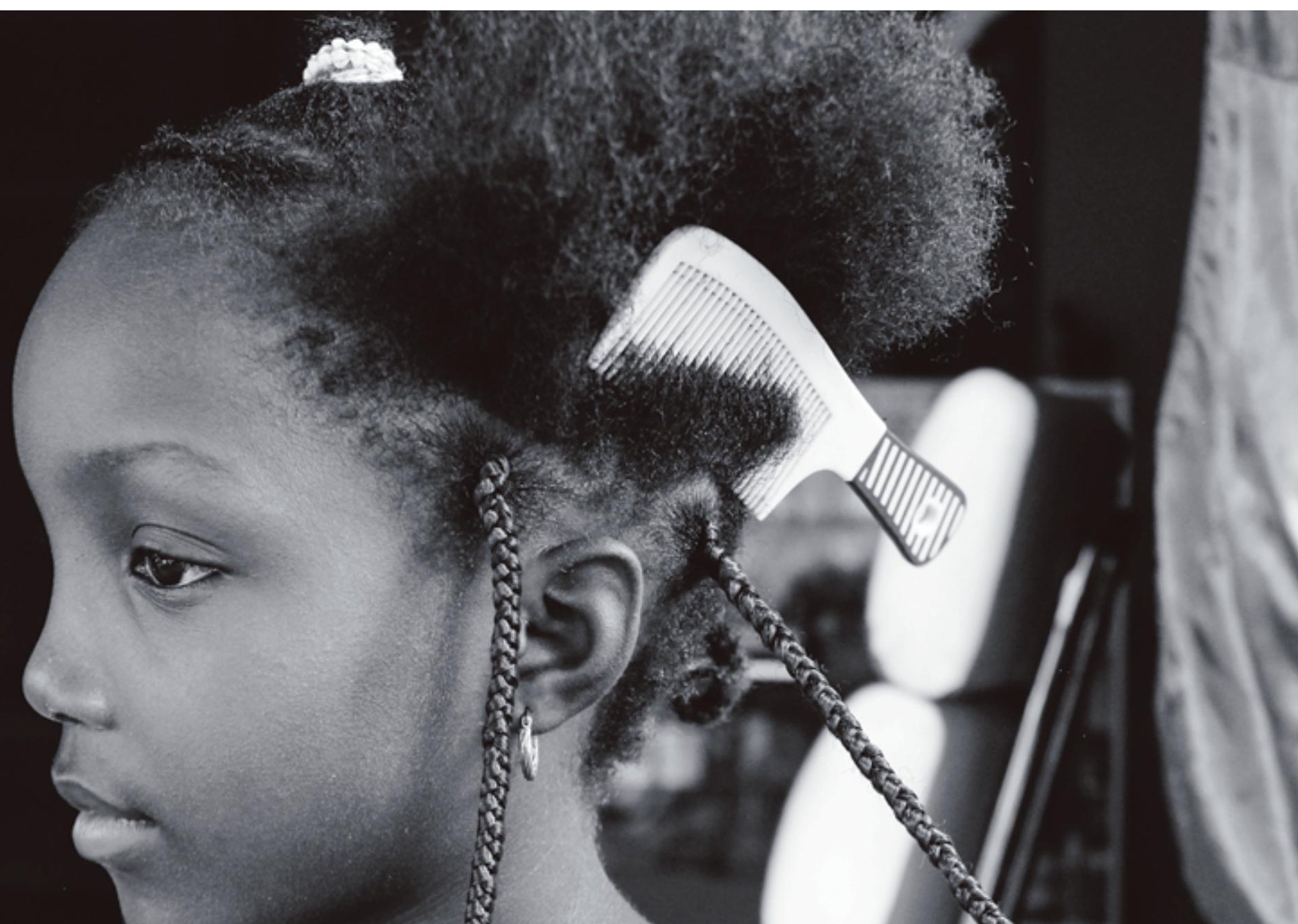



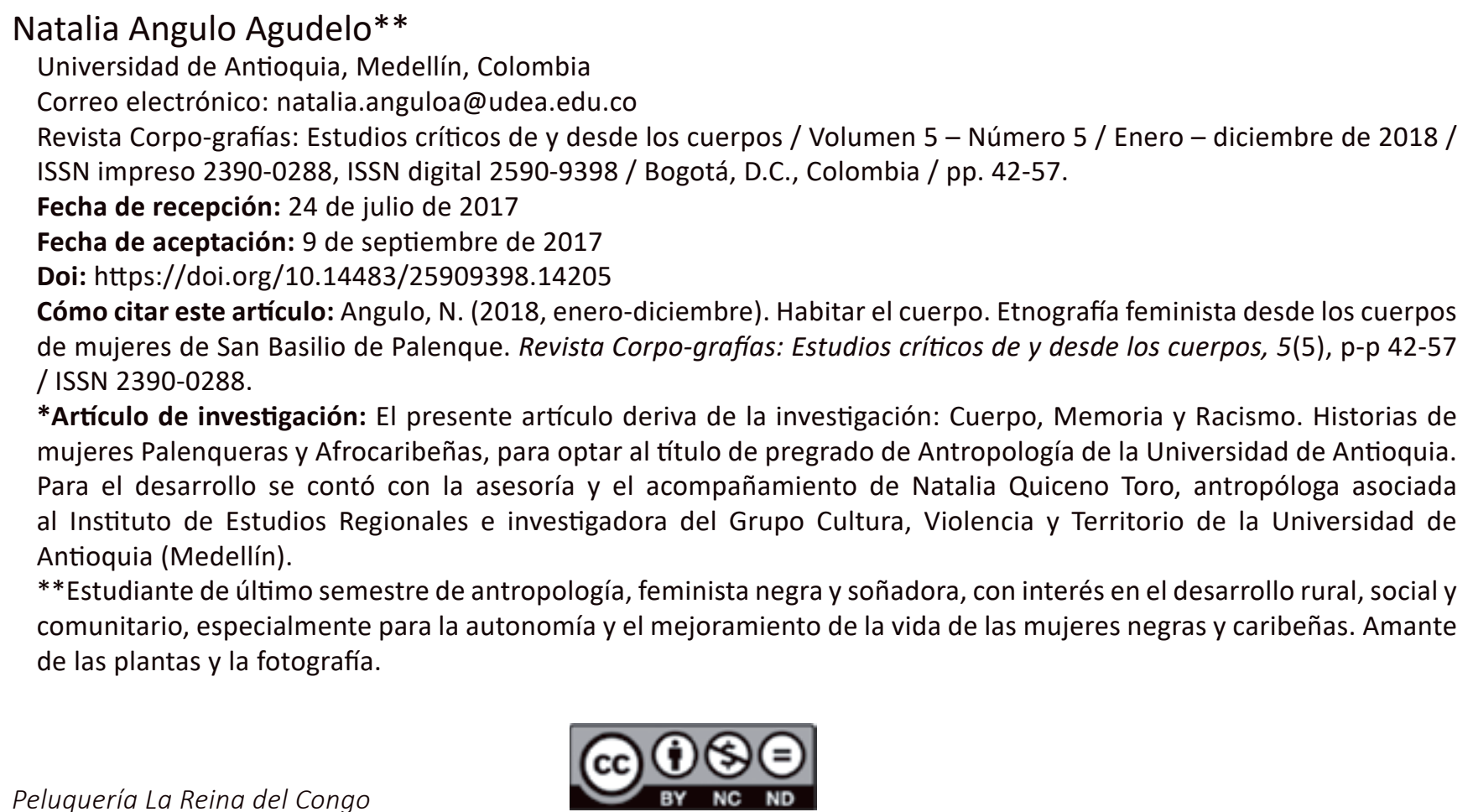


\section{Resumen}

El proceso histórico de la racialización de las personas negras en Colombia pasa de modo ineludible a través de los cuerpos racializados históricamente, resultado del colonialismo y de la vivencia de la discriminación racial y sexista. A partir de las historias de vida de mujeres de San Basilio de Palenque se ampliará la reflexión y el conocimiento de la mujer negra como sujeto social y político, donde la lucha contra el racismo y la violencia pasa de modo ineludible a través de los cuerpos; el proceso de trenzar y peinar para la mujer palenquera, es a su vez una celebración de sus propios cuerpos como parte de la lucha liberadora, alrededor de ella se transmite una gran parte de la cultura palenquera, se refuerzan vínculos a través del cuidado y se recrean prácticas de resistencia.

Palabras clave: cuerpo; cuidados; peinados; feminismo palenquero; San Basilio de Palenque.

\section{Abstract}

The historical process of racialization of black people in Colombia inevitably goes through historically racialized bodies, as a result of colonialism and the experience of racial and sexist discrimination. Based on the life stories of the women from San Basilio de Palenque, the reflection and knowledge of black women as social and political subjects will be increased, where the fight against racism and violence takes place through their bodies; for the palenquera woman, the process of braiding and brushing their hair is at the same time a celebration of their own bodies, as a portion of a liberating struggle. Around these traditions, an important part of palenquera culture is transmitted, bonds are strengthened through care and resistance practices are recreated.

Keywords: body; care hairstyles; palenquero Feminism; San Basilio de Palenque.

\section{Resumo}

O processo histórico de racialização das pessoas negras na Colômbia passa de maneira inevitável através dos corpos racializados historicamente, como resultado do colonialismo e da experiência de discriminação racial e sexista. A partir das histórias de vida de mulheres de San Basilio de Palenque se amplía a reflexão e o conhecimento da mulher negra como sujeito social e politico, onde a luta contra o racismo e a violência passa de maneira inevitável através dos corpos; o processo de trançar e pentear para a mulher palenquera, é por sua vez uma celebração de seus próprios corpos como parte da luta libertadora, ao redor dela se transmite uma grande parte da cultura palenquera, se reforçam os vinculos através do cuidado e se recriam práticas de resistência.

Palavras-chave: corpo; cuidados; penteados; feminimos palenquero; San Basilio de Palenque. 


\section{Etnografía feminista desde los cuerpos; mujeres de San Basilio de Palenque}

El propósito de este escrito es visibilizar algunas de las historias de vida de las mujeres palenqueras, que mantienen una participación activa en los procesos de organización y de lucha de sus comunidades. A partir de diferentes perspectivas raciales y de género, el cuerpo cumplirá un rol especial para entender la creación, y trasmisión de la cultura a través de una amplia red de cuidado que ha permitido mantener prácticas culturales, y una lucha histórica por la libertad.

San Basilio de Palenque, ${ }^{1}$ es reconocido como uno de los pueblos libres resultado de la insurrección esclavista más destacada de Latinoamérica, gracias a la inteligencia de hombres y mujeres que ingeniaron diversas estrategias para escapar del yugo esclavista, muchas veces su único medio para defenderse partía de sus cuerpos, el cabello por ejemplo permitió que los esclavizados que huían de las minas o de las haciendas tejieran mapas y rutas para referenciar puntos, al igual que también fue utilizado como escondites de oro con el que podrían comprar su libertad y de las semillas que utilizaban para sembrar huertos. Hoy en día, en la cultura afro, el cabello natural sigue siendo símbolo de resistencia; al tiempo que se peinan las mujeres generan lazos de amistad entre ellas y se fortalecen las relaciones de cuidado que median con las imposiciones de la industria estética. Es así que el cuerpo, cumple un lugar clave para comprender las diferentes relaciones de dominación/resistencia que se establecen, en el cuerpo se rastrean las marcas del poder, pero así mismo los procesos de sanación de estas heridas. Es necesario entonces, indagar sobre el proceso de naturalización de los cuerpos negros, concebidos como "un lugar de discriminación pero también de resistencia y contestación, y su relación con la construcción de identidad étnica y racializada que se canaliza a través del cuerpo". (Hellebrandová, 20014, p. 8). En San Basilio de Palenque, de acuerdo con el historiador Alfonso Cassiani (2012), la lucha contra el racismo y la violencia pasa de modo ineludible a través de los cuerpos, ya que son sus cuerpos, sus formas, sus estilos, lo que tradicionalmente se han convertido en centro de burla, del racismo, de la discriminación racial, devaluándolos, de manera que el proceso de trenzar y peinar para la mujer palenquera, es a su vez una celebración de sus propios cuerpos como parte de la lucha liberadora." (Cassiani, 2012, p. 35).

En las últimas décadas el cuerpo ha ido ocupando una posición destacada dentro de la teoría social. La mayoría de los teóricos se han distanciado de la concepción de un cuerpo biológicamente dado para redefinirlo como un fenómeno sociocultural e histórico (Bourdieu, 1977; Foucault, 1989; Goffman, 2006; Mauss, 1979; entre otros). Entendemos así, el cuerpo inscrito en un campo de relaciones de poderes, lo cual es el espacio donde se inscriben diferentes discursos, imaginarios, estereotipos que construimos a diario. Al ser un fenómeno sociocultural e histórico, el cuerpo padece la historia, es el que contiene la memoria corporalizada, a través de la piel, el cabello, en los movimientos, los gestos, pero también define las potencialidades y las fuerzas que expresa un cuerpo.

Es así, que alejadas de una concepción de un cuerpo biológicamente dado para redefinirlo como un fenómeno sociocultural e histórico, el cuerpo es el lugar donde se manifiestan diferentes fuerzas (políticas, sociales, económicas, eróticas, entre otras), y está atravesado por las diferenciaciones sexuales, de géneros, generaciones, étnicas, y de clases. Las cuales se constituyen como lugares desde donde se ejercen todos los poderes/saberes y por esto mismo, es el lugar privilegiado a través del cual se puede llegar a precipitar una transformación de los valores culturales y políticos (Arroyo, 2007; Pabón, 2010). Es decir, es el espacio para develar y cuestionar las diferentes formas de opresión y violencia que se imponen; promoviendo nuevas formas de subjetividad que rebasa lo coercitivo y donde es posible la resistencia.

1 Corregimiento de Mahates, ubicado a una hora de Cartagena de Indias, en el departamento de Bolívar. Declarado en el 2005 por la UNESCO, Patrimonio Cultural e Inmaterial de la Humanidad. 


\section{Los cuerpos develan nuestra historia}

Según el filósofo francés, Merleau-Ponty (1964), llegamos a entender nuestra relación con el mundo a través de la situación de nuestros cuerpos, tanto física como históricamente, en el espacio: “Lejos de ser meramente un instrumento u objeto en el mundo, nuestros cuerpos son los que nos dan nuestra expresión en el mismo, la forma visible de nuestras intenciones" (Ponty, 1964, p. 5). El cuerpo también da cuenta de una historia; Michel Foucault (1988) en Nietzsche, la genealogía, la historia, plantea que estos son lugares importantes para las genealogías, donde se manifiestan los acontecimientos y la historia, constituyéndose así como una especie de documentos vivos, que podemos abordar empleando el sentido histórico, como registros de las luchas, de la procedencia, del pasado que se reactualiza en aquellos cuerpos que albergan subjetividades de resistencias pasadas y presentes.

Reconocer y aceptar nuestros cuerpos implica un conocimiento de nuestra historia y del entorno. Acercarnos a la piel, a las facciones de nuestro rostro, al cabello, a nuestra forma de desear, y a la desnudez tanto física como simbólica, implica saber la relación que se tiene con otros cuerpos, y en esa medida cómo se establece las fronteras entre lo privado y lo público. El decidir cómo aparecer; desde los peinados, los cambios corporales, la forma como sentimos, deseamos, y expresamos, está mediado por una relación muchas veces conflictiva que intenta cuestionar, trasgredir o aceptar los imaginarios y estereotipos a partir de los cuerpos. Y todo lo que nos pasa durante la vida, nuestras experiencias, nuestro contexto, queda inscrito en nuestro cuerpo, una idea que también es central en el pensamiento de la autora, Avtar Brah (2018), quien en una entrevista plantea que los cuerpos llevan en sí las fronteras. El cuerpo es físico y simbólico: si tú eres afro/negro/, eres portador de la negritud, y la negritud tiene toda una historia detrás, tiene un simbolismo, y de eso no te puedes desprender. El cuerpo es un ente político; en el momento en que te paran en un control policial solo por tu color de piel, tu cuerpo se convierte en un ente político.

También, el hecho de ser mujeres condiciona todas nuestras acciones (Brah, 2018). Por su parte, la feminista italiana, Silvia Federici (2004) aborda la historia de la acumulación originaria del capitalismo enfocándose específicamente en los cuerpos de las mujeres sobre el trabajo reproductivo, el cuidado, en relación con el sistema económico. La autora en su libro Calibán y la Bruja, plantea que los procesos de descubrimiento, conquista, cristianización, colonización, caza de brujas y resistencias, se ubican o se encarnan en los cuerpos de las mujeres en la historia de las Américas. Se trata de unos cuerpos violados, explotados en su trabajo productivo y ubicado en relaciones de servidumbre (Federici, 2004) Hoy en día perviven estos modelos, donde el papel de la mujer dentro del trabajo, sigue siendo subvalorado y explotado.

\section{Cuerpos en contextos de violencia y racismo}

Cuando se indaga sobre la historia de la diáspora africana, los cuerpos afrodescendientes y africanos fueron considerados propiedad, teniendo un dominio parcial sobre su fuerza y al mismo tiempo sus deseos, imaginarios y placeres: encontrando en una imagen de inhumanidad un aliciente moral para justificar cualquier relación de violencia con esos cuerpos (Rojas, 2008, p. 205). Los esclavistas clasificaron a los negros por características como color de piel, pelo más rizado que otros, nariz delgada, este tipo de esclavos tenían un precio más alto en una subasta en comparación a un esclavo más oscuro o de pelo más rizado. "Esta conciencia de color que fue interiorizada por años, promovió la idea de que los negros de piel oscura y cabello rizado son menos atractivos y de menos validez. Por tanto, la esclavitud ofreció un terreno fértil al racismo". (Cassiani, 2012, p. 24). Al analizar el caso particular de las mujeres negras en el proceso 


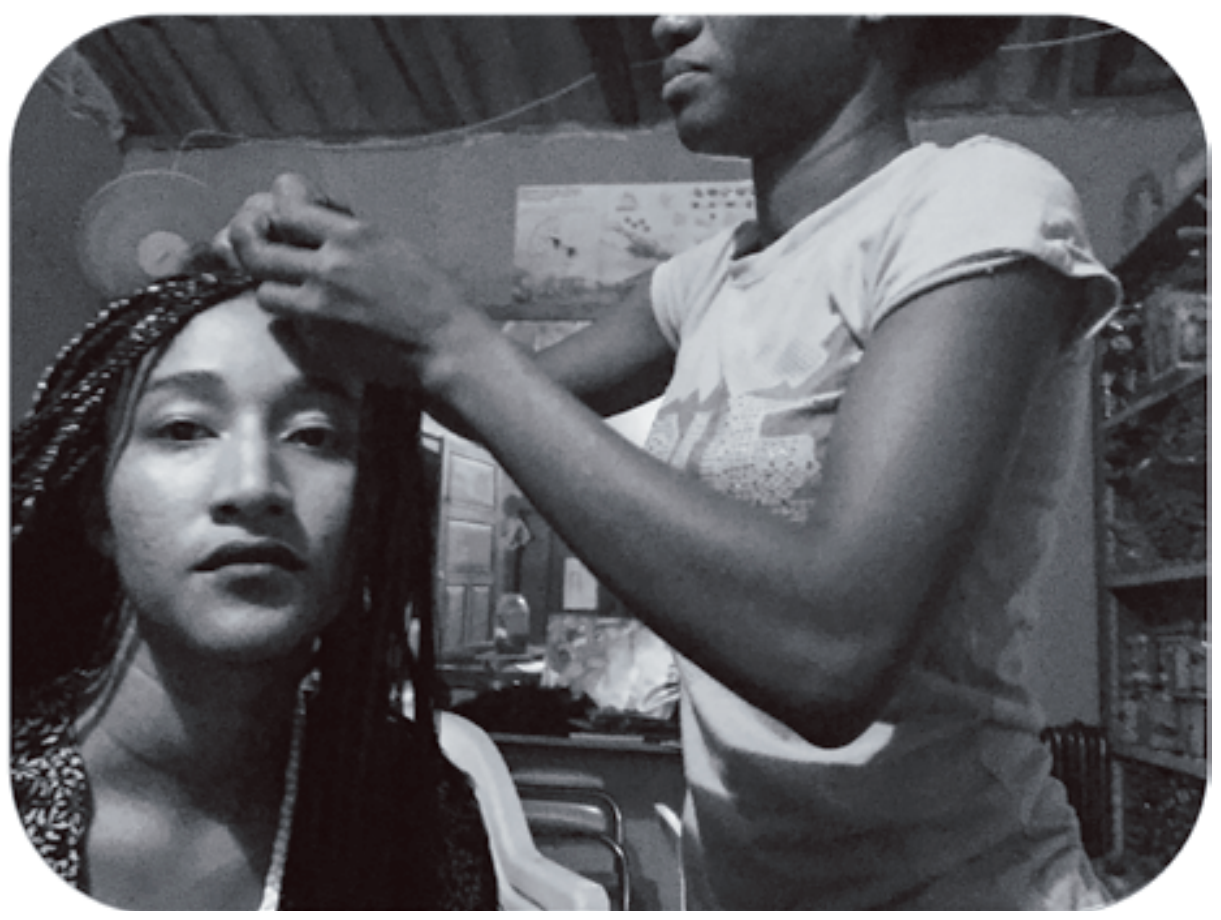

Peluquería La Reina del Congo. San Basilio de Palenque, 2017.

Fotografía por: Natalia Angulo Agudelo devastador del colonialismo, encontramos que, además de explotar su fuerza de trabajo para las labores físicas, se buscaba su capacidad sexual y procreadora para la reproducción de dicho modelo económico, que ha tenido consecuencias profundas en los imaginarios que se construyen de los cuerpos de las mujeres negras y afrodescendientes al día de hoy. Uno de los trabajos más exhaustivos, y resumido desde un ámbito histórico y antropológico es la reseña Silencios elocuentes, voces emergentes: reseña bibliográfica de los estudios sobre la mujer afrocolombiana, realizada por la antropóloga Juana Camacho Segura (2004), donde se plantea que la historia de las mujeres negras en Colombia está inscrita en un contexto simultáneo de poderes; atravesada por la lucha continua por la supervivencia y la liberación. Para la autora, la mujer negra ha sido un constructo social, la que ha sido imaginada, deseada y representada

por distintos y contradictorios estereotipos. Lo que es sumamente importante que seamos las mujeres negras que nos encontremos para reflexionar, indagar y cuestionar las prácticas donde se naturalizan y se reproducen las discriminaciones raciales y sexistas en lo cotidiano.

En este sentido, los cuerpos se vuelven una herramienta de resistencia a la imposición de la estética occidental hegemónica. Uno de los elementos que traduce bien esta estética de los cuerpos femeninos afro es el cabello. De hecho, el cabello se vuelve un lugar central de la construcción como mujeres negras-afrocolombianas. Donde se vive la presión social directa o indirecta para "blanquear" el "cabello natural" con las técnicas de planchado o alisado. Por lo tanto, el cambio y la "aceptación" del propio cabello es un asunto profundamente social y desafía el ambiente racista que modela los cuerpos (Fanon, 1973; Hellebrandová, 2014). La historia del peinado afro tiene implícita una historia de resistencia, y de trasmisión de una memoria, valores, y prácticas que recrean la propia identidad y el territorio. El proceso de trenzado, o lucir el cabello afro en sus diferentes formas, demuestra un reconocimiento y aceptación. Es a través del cuerpo que se resiste, y se celebra como parte de una lucha contra el racismo y la violencia que históricamente se ha impuesto a las mujeres negras.

En San Basilio de Palenque, los peinados se concibe como un conjunto de formas, estilos, que ha constituido un significativo acto de resistencia cultural contra un discurso dominante y la industria estética, donde la práctica de los peinados ha tenido la capacidad de provocar un cambio social y desestabilizar la relación de poder entre grupos sociales, movilizando a los cuerpos a apropiarse de los significados y darle sus propios sentidos. Las mujeres al tiempo que se peinan, comparten historias, y generan complicidades, en muchos casos a partir de las violencias que han vivido en la comunidad de diferentes maneras. Esta práctica también refuerza las redes de cuidado, 
como lo expresa Molinier (2010) se trata de un cuerpo femenino cuidando otros cuerpos, cuidando y habitando el espacio, trabajando y sosteniendo cuerpos y territorios con su trabajo corporal. Entendiendo el trabajo del cuidado como todo aquello que hacemos para reparar, sostener y mejorar nuestros cuerpos y los mundos que habitamos (Molinier, 2010, pp. 19-20).

Mara Viveros (2010), plantea que las actividades de cuidado han sido ampliamente subvaloradas, entre otras razones, porque se han concebido como tareas reservadas a las categorías sociales subalternas y como parte constitutiva que las define como tales, pero estas prácticas de cuidado son indispensables y representan un bien común que debemos preservar y fortalecer, pues nuestra condición humana de vulnerabilidad y dependencia constitutiva nos hace, irremediablemente, seres demandantes y proveedores de cuidado, por lo que todas y todos estamos inmersos en complejas redes de cuidado (Viveros, 2010, p. 6.). Estas redes sostienen comunidades alrededor de las prácticas de enseñanza de los valores, saberes, transmitiendo una memoria ancestral importante, y crea las condiciones para organizarse en colectivos y enfrentar las diferentes amenazas que atenta contra ellas. El trabajo de las mujeres alrededor de prácticas del cuidado han sostenido el sistema económico y político, pero sus trabajos han sido desvalorado y muchas veces invisibilizados cuando nos referimos a los estudios sociales y comunitarios. Obedeciendo a prácticas sexistas, amparadas en lo tradicional que no permite reconocer el papel de las mujeres en las comunidades rurales.

\section{Los peinados en Palenque, una forma de resistencia y contestación del cuerpo}

En San Basilio de Palenque, encontramos los peinados que dan testimonio de resistencias que han pervivido y se han transformado en el tiempo, de acuerdo a la creatividad de las mujeres que peinan con ligereza el característico cabello afro, demostrando que la imaginación, la vanidad y el arraigo cultural no tienen límites a la hora de hacer un perfecto peinado. El proceso de trenzado, o lucir el cabello afro en sus diferentes formas, demuestra un reconocimiento y aceptación de sí mismas. Es a través del cuerpo de estas mujeres que se resiste, y se celebra como parte de una lucha contra el racismo y la violencia que históricamente se ha impuesto hacia las mujeres negras.

En palenque la memoria está latente en cada canto, gesto, movimiento, en cada peinado, que conforman un gran número de formas, estilos, nombres, y significados o historias, creando así códigos que se convierte en un complejo medio de una comunicación del cuerpo, donde incluso "se habla a través de los peinados", siendo las mujeres las protagonistas de este oficio, que además de ser un medio para alcanzar su libertad, es el medio de muchas para sobrevivir.

El historiador palenquero, Alfonso Cassiani (2012) ha hecho aportes valioso acerca la historia de Palenque, en cuanto a los peinados, el autor plantea en su obra: Trenzando sendero: resistencia, libertad y cultura. Ma Tregsa Ku Kamino Rria Ma Kuttu, Libertad I Kuttura, que, en esta sociedad estructurada en los cimientos de una cultura de la dominación, en la que los diversos sectores sociales populares deben luchar en forma permanente para reconocerse a sí mismos, el proceso de trenzado que realizan las mujeres negras constituye entre otras cosas la posibilidad de estar en contacto con sus propios cuerpos, de reconocerse a sí mismas. Ya que son sus cuerpos, sus formas, sus estilos, lo que tradicionalmente se han convertido en centro de burla, del racismo, de la discriminación racial, devaluándolos, de manera que el proceso de trenzar y peinar para la mujer palenquera, es a su vez una celebración de sus propios cuerpos como parte de la lucha liberadora (Cassiani, 2012, p. 35). 
Más allá de una estrategia política de resistencia, es un acto cotidiano que hace parte de la misma cultura palenquera, es un rasgo que pretende ser diferenciador y propio de las mujeres y se transmite a través de diversas prácticas pedagógicas y educativas insertas en la cultura palenquera. El arte del tejido de los peinados afro y palenqueros, reúne una cantidad de estilos, formas, como tropas, twist, afros, trenzas, bordebalais, turbantes, cada uno lleva significados diferentes de acuerdo a diferenciaciones sexuales, género, generaciones, étnicas, y de clase.

Es innegable el papel femenino para conservar la memoria de los saberes ancestrales desde los valores éticos, morales, estéticos, alrededor de los saberes gastronómicos, artísticos, medicinales, que se transmiten de madre, abuela, tía a niñas, jóvenes y mujeres en diferentes líneas de parentesco, teniendo mayor relevancia la madre, como encargada de transmitir la cultura de origen en acciones cotidianas.

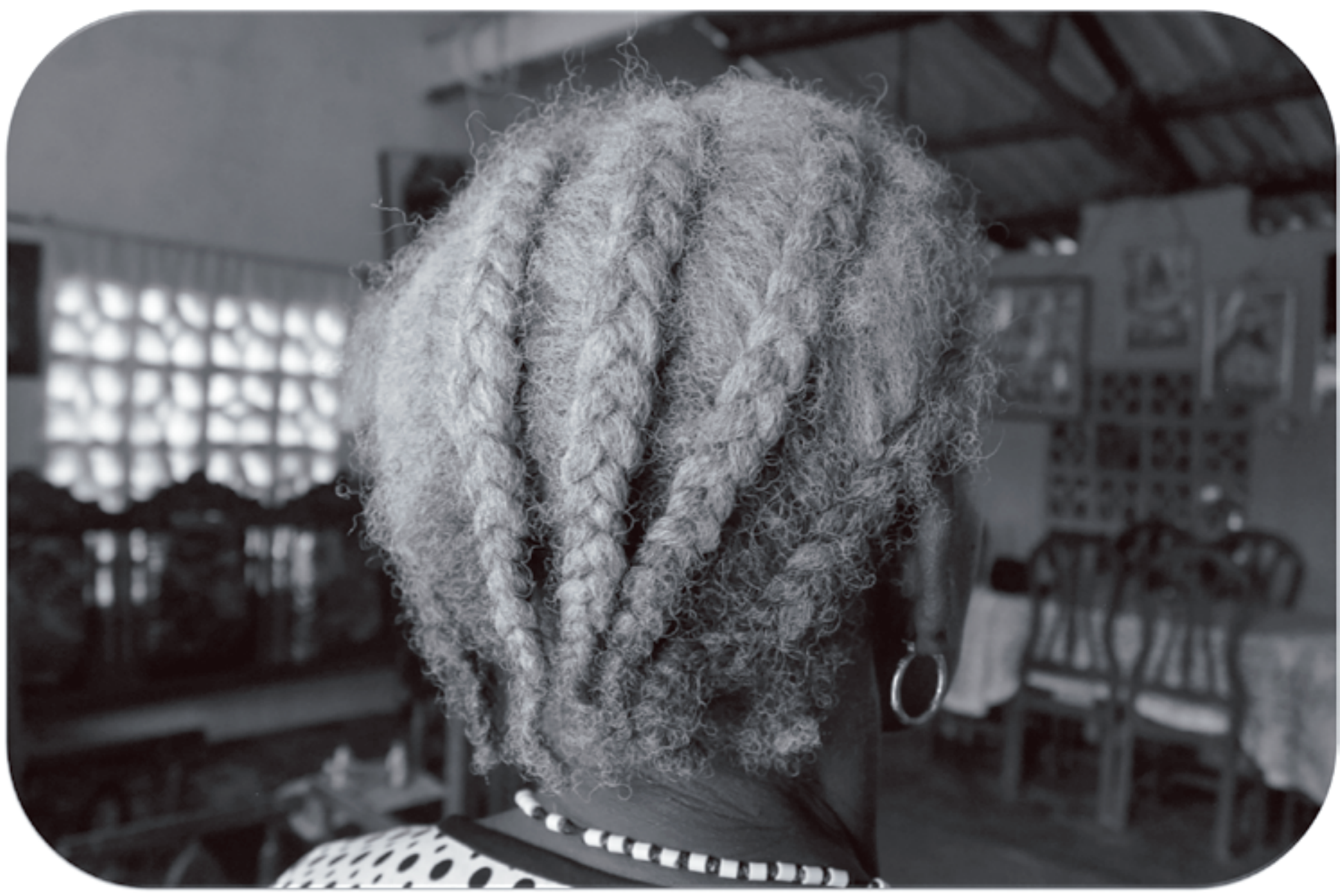

Peinados

San Basilio de Palenque, 2017

Fotografía por: Natalia Angulo Agudelo 
El trenzar es un arte que es transmitido y aprendido principalmente por observación, siendo la infancia un momento importante para la construcción de estética, prácticas de cuidado del cuerpo, y de respeto de otras personas como transmisoras de estos saberes. Elida Cañate, es una reconocida peluquera del pueblo, que conoce con mucha propiedad los diferentes tipos de peinados y sus historias. Estudió licenciatura en Ciencias Sociales, pero su vocación desde pequeña ha sido el peinado, y por la necesidad de hacerse cargo de su hija, desde hace algunos años decidió con su hermana emprender una peluquería que lleva como nombre "La Reina del Congo". Ella describe su acercamiento a los peinados de la siguiente manera:

Aprendí a peinar a los 11 años y mis primeras trenzas recuerdo que fueron las bordebalais, y las trenzas libres, el método consistía en observar y luego poner en práctica lo que veía que hacían sus hermanas. Para eso, buscaba cualquier material que pudiera dividir en tres cantos, como retazos de telas, hilos, cabuyas, y así, hasta que iba quedando todo trenzado (Entrevista a Elida, 2017).

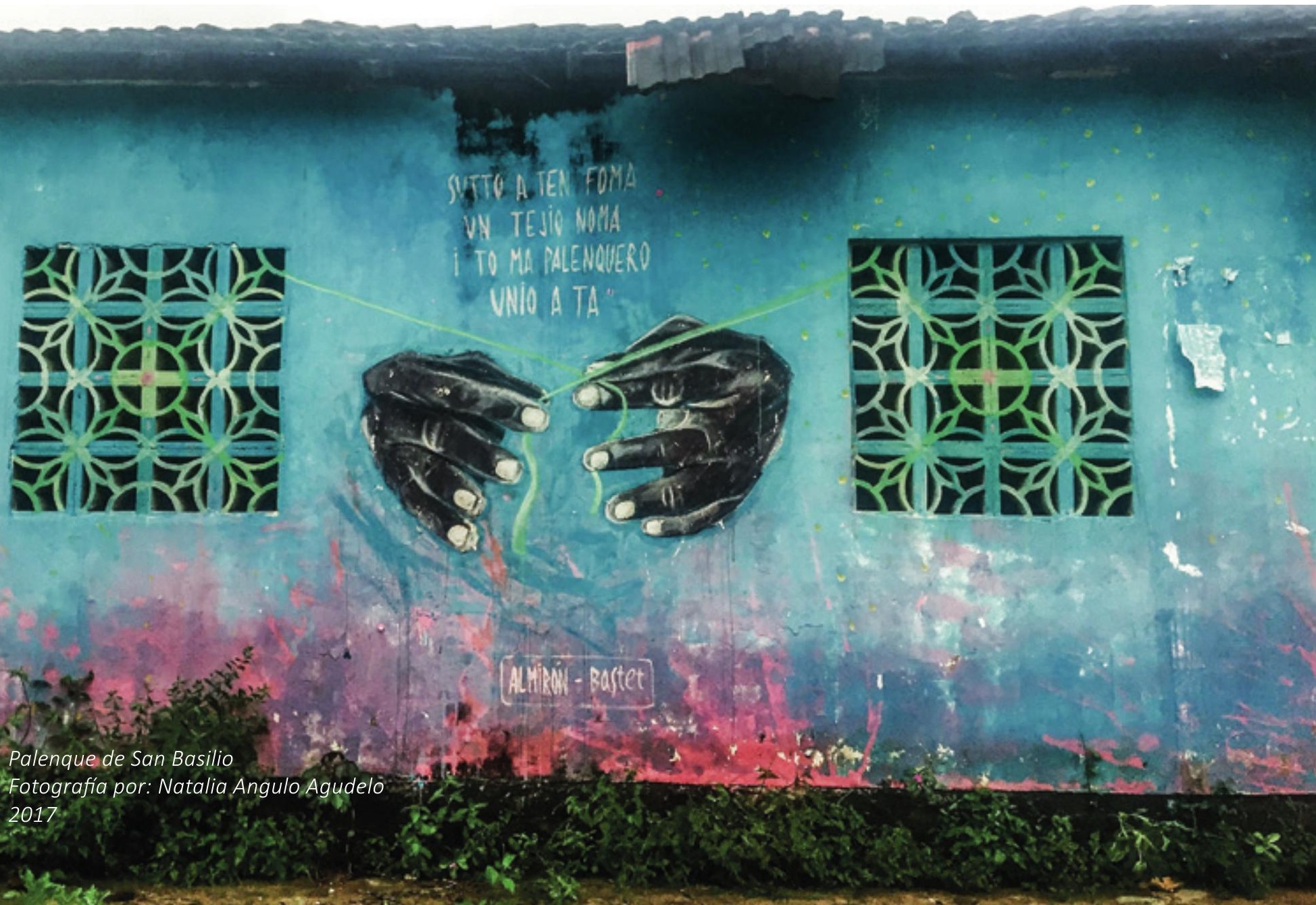


Esta práctica, es tan importante dentro del mismo proceso de crianza, donde desde niñas, se establece una relación de estímulo y creatividad con el propio cabello y el de las demás. Las niñas aprenden lo que ven a su alrededor, teniendo mucha importancia el juego, por su papel de enseñanza más eficaz y de socialización, en la medida que afianza los vínculos de confianza, aprendiendo a sentirse bien y ganando seguridad en sí mismas, María Hernández menciona:

Inicié peinando a las muñecas y a amigas, aprender es fácil, me di cuenta que era de una forma o de otra, porque veía a mi hermana y mis propias manos me indicaban que era así y me iba especializando más (Citado por Cassiani, 2012, p. 24).

Por su parte Alba Luz, madre de una joven peinadora, cuenta la importancia de la relación que se establece desde pequeña con el cabello, y el acompañamiento de la madre, que es fundamental en el proceso de aprender a tejer con el cabello, descubriendo poco a poco la creatividad y el manejo de las manos, la madre comenta:

En Palenque las niñas aprenden a peinar desde que en su momento ya tienen movimiento en sus manos ellas ya quieren peinar e inician peinándonos a nosotras las madres /nos quieren soltar el cabello, hacer las trenzas, nos enredan, nos peinan, nos jalan, desde ese momento se puede decir, desde unos tres o cuatro años, y ellas quieren estar jalándonos el cabello a nosotras las madres y quieren estar tejiendo y ahí esa es su práctica, y te puedo dar un ejemplo, mis hijas son peinadoras, una que tiene once años y ya peina en eventos, así sucesivamente, las niñas todas se peinan y hacen intercambio, o sea la una peina a la otra. (Citado por Cassiani, 2012).

El proceso de enseñanza no es impositivo, se respeta el ritmo que tiene cada niño o niña, procurando siempre cuidar de la creatividad y espontaneidad que se genera en la práctica, que no ocurre solo en el peinado, sino en otras artes. Durante el tiempo que estuve en Palenque, pude observar el acercamiento que tienen algunos niños y niñas con algún instrumento, en especial el tambor. Conversando con los mayores, me contaban que se suele dejar al niño o niña durante un tiempo con el instrumento, para que juegue, lo conozca, descubra y se familiarice con el sonido. Luego

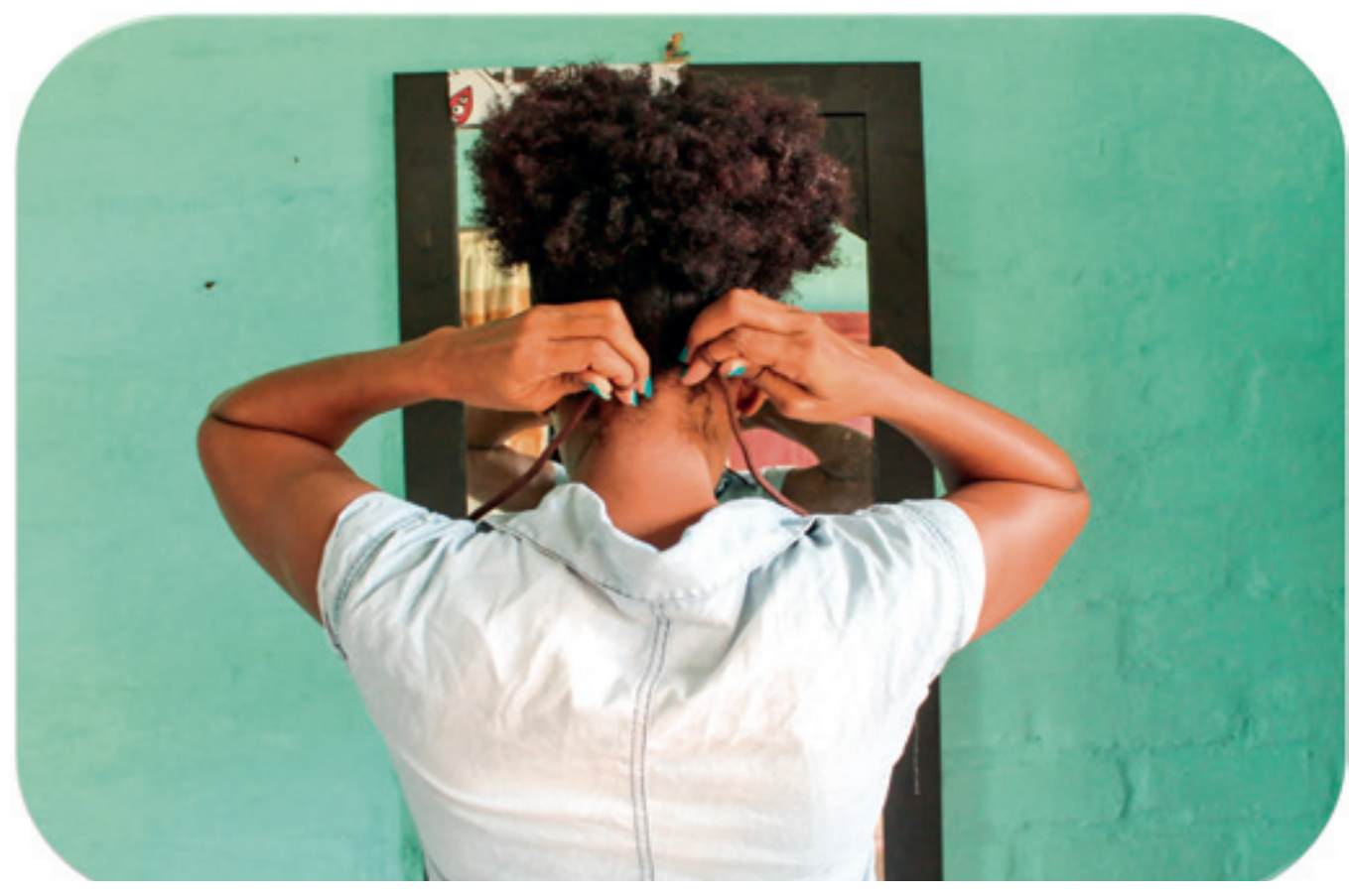

Mujer y cuidados. San Basilio de Palenque, 2017 Fotografía por: Natalia Angulo Agudelo 
se le guía, más no se le dice que está mal o está bien. En el peinado, sucede algo similar, Yadelsi Cañate, hermana de Elida, y peluquera en La Reina del Congo, menciona lo siguiente:

Los peinados aquí no se aprenden con que vamos a la escuela que nos van a enseñar, eso es únicamente viendo, a veces lo corrigen a uno y a veces no, por ejemplo la hermana mía (Elida), como ella peina y aprendió primero que yo, alguna trenza que yo hacía ella me decía / Uh, eso está maluco, más no me decía es así, me decía que estaba maluco y ya, con esa crítica, yo buscaba para mejorar (Entrevista a Yadelsi, 2017).

El historiador Alfonso Cassiani, describe que "el proceso de aprendizaje madura entre los catorce y los dieciséis años cuando las niñas ya han aprendido a realizar peinados complejos e incluso a realizar innovaciones propias, es en este momento en el que se define quienes se dedican a profundizar en el arte del peinado palenquero". Siendo Palenque un destino etnoturístico, escenario en el cual los peinados se constituyen en uno de los principales atractivos. Muchas de las mujeres que aprender el arte del peinado, consiguen a través de este oficio junto con la venta de dulces, el sustento para mantener a su familia. Más adelante profundizaremos esta relación entre la economía y los peinados.

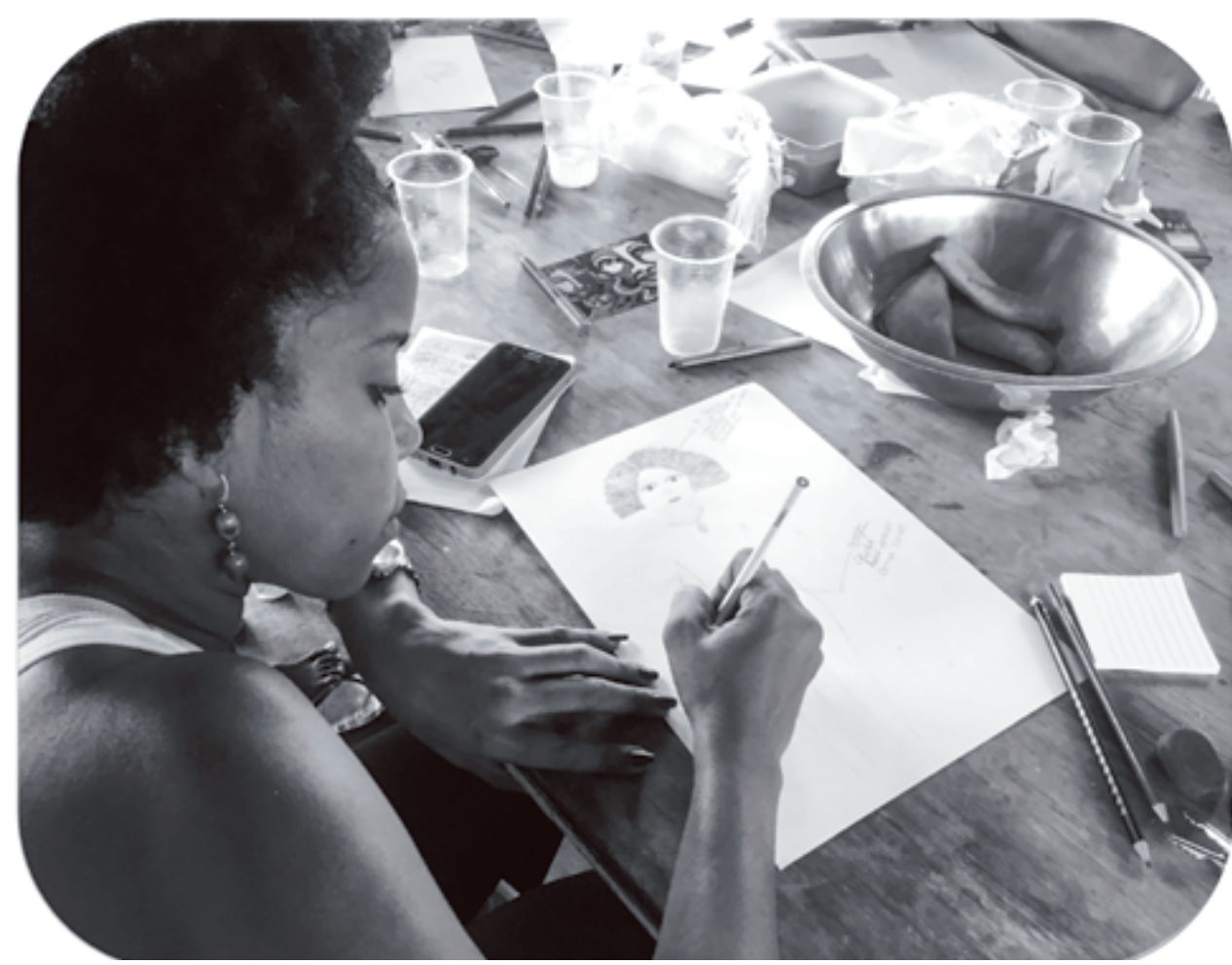

Líder de la comunidad.

Taller de Cartografía del cuerpo con Kasimba de sueño

San Basilio de Palenque, 2017

Fotografía por: Natalia Angulo Agudelo
Retomando las prácticas cotidianas que conforman los peinados en palenque, es importante aclarar que se distinguen diversidad de peinados, y se pueden diferenciar entre los tradicionales y los de innovación, estos últimos se distinguen por su versatilidad continua y por su diversidad y creatividad, gracias al cabello sintético lo cual facilita la dinámica creativa que caracteriza a los peinados nuevos. "Los peinados nuevos, son expuesto principalmente por las jóvenes, aun cuando algunas señoras mayores también los usan, sus usos están determinados por lo múltiples escenarios comunitarios" (Cassiani, 2010, p. 61). El cabello en las comunidades negras, en particular en Palenque, es como el cordón umbilical que conecta simbólicamente con África, no solo desde la ancestralidad y una memoria tradicional de los peinados, sino que inclusive hoy más que nunca con los peinados de innovación, que nacen a partir de las referencias que se pueden ver a través de las redes, o los medios virtuales; Elida, hoy 


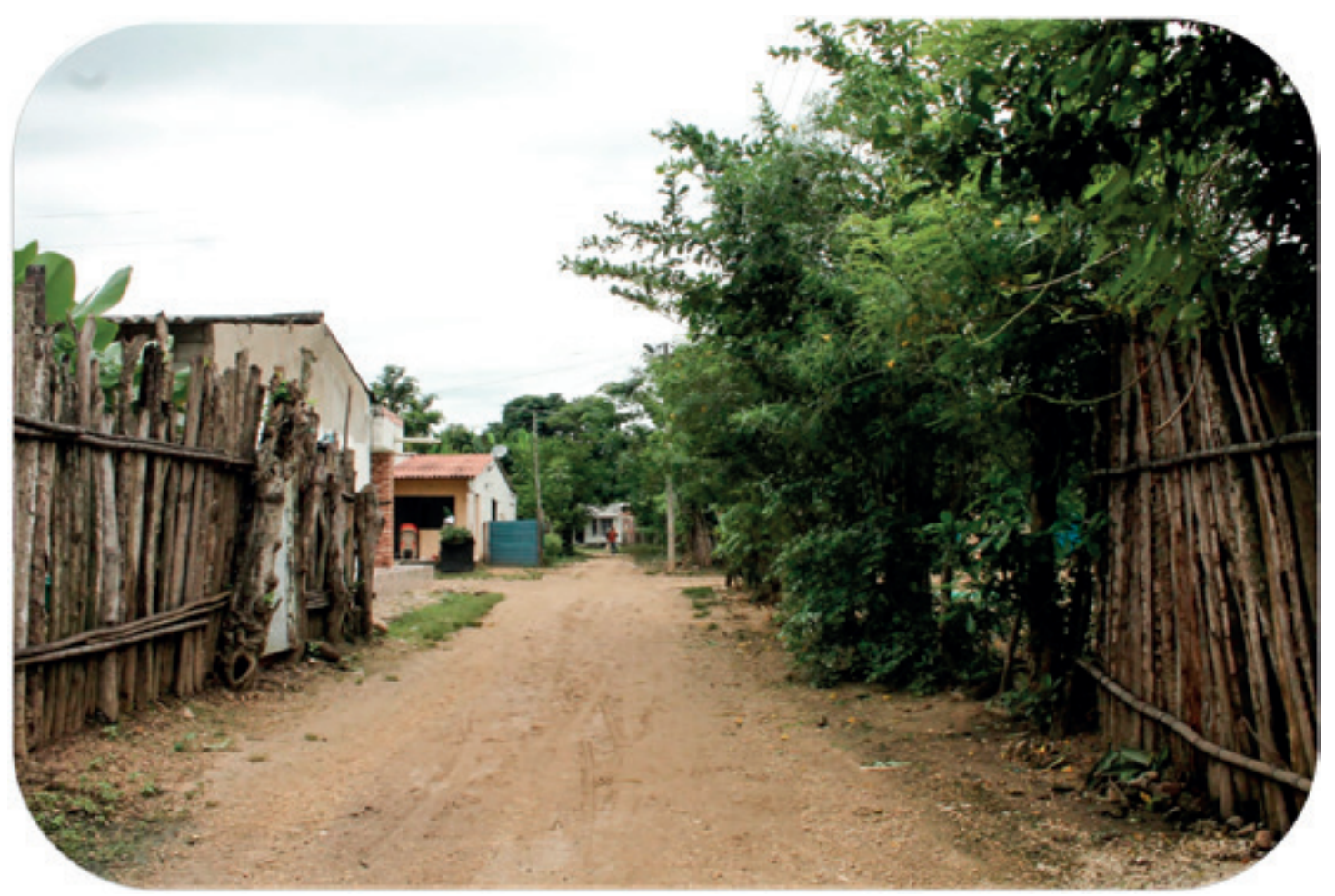

Calles de San Basilio de Palenque Fotografía por: Natalia Angulo Agudelo 2017

en día por medio de la tecnología se ha podido reconocer ese vínculo con algunos pueblos de África occidental, donde el trenzado es un código que permite mantener y reforzar un vínculo. Elida, comenta que estudia y se inspira viendo algunos videos, fotografías de peinados que se hacen en algunas partes de África, que permite entender las diferencias y buscar las similitudes, recogiendo lo que le interesa y que sirva de material para continuar creando nuevos diseños que recrean la cultura palenquera. Por medio de las redes, ella puede ver cómo están allá, los peinados, turbantes, y conoce más sobre la historia de los peinados. Siguen demostrando la conexión que se tiene con la ancestralidad pensada desde hoy, así mismo con la naturaleza vegetal y animal, y del medio en que se encuentra.

Varios de estos referentes africanos, que es posible observar, gracias a trabajo artísticos, como las fotografías de J.D Okhai Ejeikere -nacido en Nigeria, 1930- y que las ha venido recopilando de la calle, el trabajo, celebraciones; alrededor de 15000 fotografías, teniendo la oportunidad de conservar actos y mostrarnos solo una parte importante de la cultura nigeriana, donde las mujeres transmiten las tradiciones, logrando una espectacular reivindicación de la cultura popular de diferentes pueblos del África subsahariana.

Las mujeres crean cultura a través del cabello. Al tiempo que se peinan generan lazos de amistad entre ellas, se fortalecen las relaciones de confianza. En una ceremonia familiar en la que las madres, tías y abuelas enseñan los peinados a las niñas, posteriormente se traduce en la construcción de confianza entre hermanas, primas y amigas, que en medio de un ambiente de confidencialidad, en el que algunos casos no se permiten la presencia de los hombres, se reúnen durante horas a peinarse mutuamente. 
En estos espacios, que hoy en día en su mayoría son formalmente las peluquerías, pero también en los patios, las salas, en el arroyo, el salón de clases, en el asiento del bus. Esta red o grupo de "amigas" muchas veces se constituyen a partir de los kuagros, ${ }^{2}$ que es sin lugar a duda un dinamizador de la cultura en Palenque, teniendo el peinado un lugar muy importante en el grupo, porque se convierte en un elemento de identificación del kuagro. La relación entre los kuagros y los peinados palenqueros se describe como lo siguiente:

Decimos desde los kuagros nos hacemos un peinado para impresionar a todo el mundo, y nos vestimos igual, nos hacemos el mismo peinado. Además en los kuagros nos peinamos mutuamente, el kuagro ayuda para mantener la tradición del peinado y en su mayoría en el kuagro se aprende a peinar (Citado por Cassiani, 2012, p. 71.).

Se crean lazos de solidaridad, confianza, inclusive de gustos afines. Cuando por diferentes circunstancias o motivos las mujeres tienen que viajar a estudiar o trabajar a otros lugares, y se ven "solas" o sin la cercanía de mujeres afro que manejen el arte del peinado, es una de las razones por las cuales algunas mujeres deciden alisarse el cabello, ya que les cuesta encontrar a otras personas que puedan peinarlas y que al mismo tiempo se genere una complicidad que haga resistencia ante las imposiciones hegemónicas estéticas y de prácticas culturales que se agudizan en las ciudades.

En cuanto al alizer hay varias posiciones, hay quienes opinan que no necesariamente es visto como una amenaza porque es algo transitorio, mientras otras consideran, como Elida, que "el alizer es un proceso de blanqueamiento, e imposición social que te hace creer que lisa te ves más bonita, algunas les toca alisarse por obligación" (Entrevista a Elida, 2017). El alizer para muchas mujeres puede ser un aspecto que les permita entrar "a la moda", innovar, cambiar, un factor que está muy presente en la vida social y cultural en Palenque. Retomando siempre los peinados propios. Muchas mujeres, intercambian, se alisan, se trenzan, se ponen extensiones, pelucas, incluso se rapan el cabello, buscando en cada momento una libertad de expresión, creatividad, cambio; que muchas veces son estéticas que cuestionan las prácticas tradicionales de lo que significa o no ser palenquero o palenquera, en un juego de resistencia ante las imposiciones que generan las tradiciones.

El cabello, como hemos mencionado es un elemento muy importante tanto del proceso de racialización y del blanqueamiento como de la reivindicación y resistencia, corre también el riesgo de volverse un elemento esencialista según el cual se valoría lo "auténticamente negro". Ya que la decisión de algunas mujeres de alisarse el cabello es compleja y está atravesada por muchos factores estéticos, sociales, raciales, de clase o de género, que se cruzan y manejan según los contextos espaciales y temporales (Hellebrandová, 2014).

Independientemente del modo de componer el cabello que las mujeres negras escogen individualmente, es evidente que el grado en que sufrimos la opresión y explotación racista y sexista afecta el grado en el que nos sentimos capaces tanto de auto-amor como de afirmar una presencia autónoma que sea aceptable y agradable para nosotras mismas, ante lo que bell hooks escribe lo siguiente:

Las preferencias individuales (estén o no enraizadas en el auto-odio o no) no pueden negar la realidad de que nuestra obsesión colectiva con alisar el cabello negro refleja la psicología de opresión y el impacto de la colonización racista. Juntos, racismo y sexismo les recalcan diariamente a todas las mujeres negras por la vía de los medios, la publicidad, etc. que no seremos consideradas hermosas o deseables si no nos cambiamos a nosotras mismas, especialmente nuestro cabello. No podemos oponer resistencia a esa socialización si negamos que la supremacía blanca informa nuestros esfuerzos por construir un sí mismo y una identidad (hooks, 2005, s.p).

2 Grupos conformados por los miembros de un mismo rango de edad en los cuales se fomentan lazos de amistad que llegan a constituir grupos de apoyo, de parentesco. 
Como lo señala bell hooks, el cabello alisado está vinculado histórica y actualmente a un sistema de dominación racial que les inculca a las personas negras, y especialmente a las mujeres negras, que no somos aceptables como somos, que no somos hermosas. Por lo que es un acto político, trabajar en el cuidado y amor de nuestro cuerpo, celebrando nuestra libertad y aceptación, desde el respeto profundo de nuestros rasgos. Traduciéndose. Así como el hecho más importante que las mujeres negras opongan resistencia al racismo y el sexismo por todos los medios; que todo aspecto de nuestra autorepresentación sea una resistencia radical por medio de nuestros cuerpos.

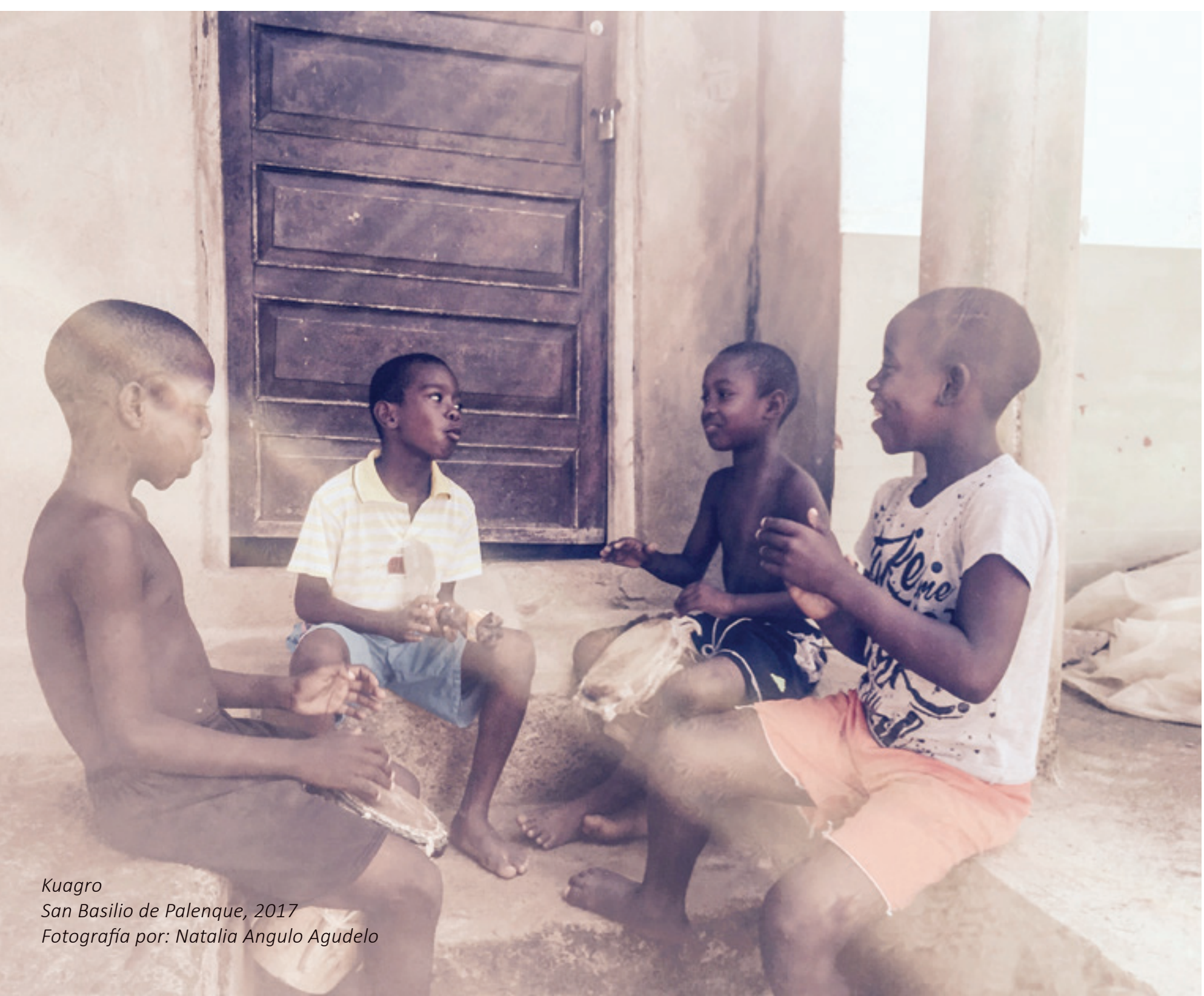





\section{Referencias}

Bourdieu, P. (1977). Outline of a Theory of Practice. Cambridge: Cambridge University Press.

Butler, J. (2001). El género en disputa. El feminismo y la subversión de la identidad. México: Paidós.

Brah, A. (2018) La identidad siempre es un proceso, nunca un producto final. El salto. En línea https://www.elsaltodiario.com/ pensamiento/entrevista-avtar-brah-identidad-siempre-proceso-no-un-producto-final

Camacho, J. (2004). "Silencios elocuentes, voces emergentes: reseña bibliográfica de los estudios sobre la mujer afrocolombiana". En M. Pardo, C. Mosquera y M. C. Ramírez. Panorámica afrocolombiana. Estudios sociales en el Pacífico, pp. 167-210. Bogotá: Instituto Colombiano de Antropología e Historia-Icanh, Universidad Nacional de Colombia.

Cunin, E. (2003). Identidades a flor de piel. Lo "negro" entre apariencias y pertenencias. Categorías raciales y mestizaje en Cartagena. Bogotá: Instituto Colombiano de Antropología e Historia. Uniandes.

Cortés, L. (2009). Proyecto "quieto Pelo" realizado con mujeres Buenaventura. Medellín digital.

En línea http://esferapublica.org/nfblog/wp-content/uploads/2015/04/MC9_Retratos-en-blanco-y-afro-LAngulo-SAstridEscobarweb.pdf

Cassiani, A. (2012) Trenzando sendero: resistencia, libertad y cultura. Ma Tregsa Ku Kamino Rria Ma Kuttu, Libertad I Kuttura. Cartagena: Ediciones Pluma de Mompox.

García, A. (2016). Mujeres campesinas, afrodescendientes e indígenas en Colombia, prácticas políticas y cotidianas del cuidado. Colombia. En línea: https://www.imagenesmovimiento.com/assets/artmujeresruralesetnicascolombiaandrea.pdf

Goffman, I. (2006) [1963], Estigma. La identidad deteriorada. Buenos Aires: Amorrortu.

Foucault, M. (1988). Nietzsche, La Genealogía, La Historia. Barcelona. Pre - Textos.

Foucault, M (1989), Vigilar Y Castigar. Nacimiento de la prisión. Buenos Aires: Siglo XXI.

Fanon, F. (1973). Piel negra, máscara blanca. Buenos Aires: Editorial Abraxas.

Hellebrandoyá, K. (2014). Escapando a los estereotipos (sexuales) racializados: el caso de las personas afrodescendientes de clase media en Bogotá. Revista de Estudios sociales. En línea http://www.redalyc.org/comocitar.oa?id=81530871008

Hooks, B. (2004). "Mujeres negras: dar forma a la teoría feminista”. En Otras inapropiables. Feminismos desde las fronteras. Madrid: Traficante de sueños.

Lawo y Morales. (2015). Estéticas decoloniales del peinado afro e interculturalidad: experiencia San Basilio de Palenque, Colombia.

Mauss, M. (1979). “Técnicas y Movimientos Corporales”. En Sociología y Antropología. Madrid: Tecnos.

Meano, L. (2016). Vivir en la frontera. Madrid: La Catarata.

Merleau-Ponty, M. (1964). The Primacy of Perception. Evanston, Northwestern:

University Press.

Molinier, P. (2010). El trabajo del cuidado y la subalternidad. Escuela de Estudios de género. Bogotá: Universidad Nacional de Colombia

Pabón, C. (2010). Construcción de cuerpo. En línea https://es.scribd.com/doc/45332816/Pabon-Consuelo-Construcciones-deCuerpos

Rojas, A. (Coord.). (2008). Cátedra de Estudios Afrocolombianos. Aportes para maestros. Popayán, Colombia: Universidad del Cauca. Viveros, M. (2010). “Introducción”. En El Trabajo del cuidado y la subalternidad. Escuela de estudios de género. Bogotá: Universidad Nacional de Colombia. 